\title{
Analysis Influence of Consumer Behavior to Purchase Organic Foods in Jakarta
}

\author{
Antonius Siahaan*, Jeffry Thiodore \\ Faculty of Business and Communication, Swiss German University, Tangerang, 15143, Indonesia, \\ "Corresponding author. Email: antonius.siahaan@sgu.ac.id
}

\begin{abstract}
This research aims to prove whether there is positive correlation among theory of planned behavior variables and give suggestions to the organic food producers to create and formulate a preferable marketing strategy, achieve better sales performance and to support organic food growth in Jakarta. A survey was conducted during June, $12^{\text {th }} 2017$ to July $3^{\text {rd }}$ 2017. A sample of 400 respondents were distributed to citizens who stay in the Jakarta area and know about organic food. The data was analysed using Structural Equation Model (SEM) and descriptive analysis to see the features of data collected and their relationship on attitudes, subjective norms, perceived behavioral control to intention as mediator to purchase organic foods in Jakarta. The SEM results of this study show that attitudes and perceived behavioral control have influence on intention, which perceived behavioral control has "strong" correlation. While, the subjective norms have not influenced the intention. As a mediator variable, the intention has shown a "very strong" correlation to purchase decisions on purchasing organic foods.
\end{abstract}

Keywords: Attitude, Consumer behavior, Intention, Perceived control behavior, Purchase decision, Theory of planned behavior, Subjective norm.

\section{INTRODUCTION}

Agriculture remains the key sector to accelerate economic development in many developing countries in Asia, including Indonesia. The necessity of an ecologically friendly farming system coupled with consumers' desire for food free from synthetic chemicals has made organic farming a growing agricultural enterprise in developed countries. Several governments have announced ambitious targets of organic agricultural production to ensure sustainable and affordable production of organic products, and the market for organic foods has rapidly grown in developed countries. Hsieh [1] revealed that, in developing countries such as Indonesia, organic farming still targets mainly local consumption. Most farmers work at family farms with small-scale production. Hsieh concluded that government policies should support the development of farm extension, post harvesting technology, and marketing strategies. Standards and an inspection system are urgently needed to address the organic quarantine system.

Nowadays, people are very aware of putting more attention on healthy living and carrying out activities with a fit body triggers the emergence of ideas to consume more organic foods in life. Development of organic agriculture in Indonesia can be traced in early 1970 when the green revolution happened, Indonesian farmers were being introduced to use chemical fertilizers and pesticides to increase yield. However, it led to several negative effects not only on the environment but also in human's body (consumers). For instance, the pesticides will give impacts to increase the potential of cancer, miscarriage for women, and human immunity.

According to the latest data from the Research Institute of Organic Agriculture (FiBL) and the International Federation of Organic Agriculture Movements (IFOAM-Organics International), total area of organic agricultural land in Indonesia is 130,384 hectares in 2015, which increase about $13 \%$ compared to 2014 [2-3], as shown in Figure 1. This achievement resulted in Indonesia as fifth largest organic agriculture land in Asia, after China, India, Kazakhstan and Philippines. Total area of organic agricultural land is equal to $0.2 \%$ with respect to the total area of agricultural land in Indonesia. Of this total organic agriculture area, only 67,426 hectares have been certified as organic agricultural land with 1,142 hectares undergoing the certification process. Indonesia has many opportunities in increasing organic agricultural land by increasing the 
competitiveness of organic products in the domestic market.

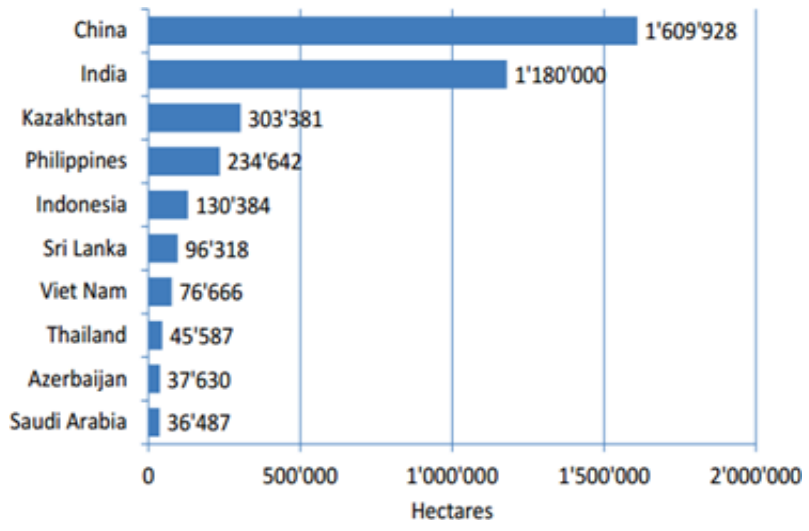

Figure 1. Top ten countries with largest organic area in 2015 [2-3]

Among Asia country, Indonesia is standing at fifth place below Philippines on fourth which have 130.384 hectares of organic foods. China is the one who stands at the first place with the largest organic area by 1.609 .928 hectares. This area is almost 12 times of the total Indonesia organic area. The area of organic food is shown clearly below Figure 1. is an archipelago country with more than 17,000 tropical islands and is about $5,000 \mathrm{~km}$ east to west. It is the fourth most populous country in the world (258 million people in 2015) and has vast natural resources, which are prime assets for agribusiness development. The total land area in Indonesia in 1992 was about 192 million hectares. Through 1998, about 66 million hectares, or only $34 \%$, was used for agriculture and other purposes. Arable land for food crop production was about 29 million ha of the 130 million ha available in 1998. It has been estimated that there are 17 million ha of idle land that could potentially be used for organic farming. In particular, there are large amounts of potentially usable land available in Sulawesi, Kalimantan, and Sumatra [2-3].

According to Indonesian Organic Alliance (AOI), the domestic market share of organic food is dominated by fruits and vegetables $(21 \%)$, followed by rice $(20 \%)$ and honey $(10 \%)$. Hence, the very first step from the campaign on healthy living is to begin with starting to consume organic food such as vegetables and rice.

In the late of 2010, Indonesian government through the Ministry of Agriculture has launched programs to increase the public awareness of healthy lifestyle such as GO Organic with the purpose to popularize organic agriculture to consumers, farmers, and market participants and to wider the community. At first people consume food without considering whether the food contains harmful chemicals or not. As the development of the information of organic, some communities began to switch from non-organic to organic. Most people start to believe organic foods are safer to be consumed because of chemical free cultivation processes.
Consumer choices and behaviour on purchasing organic foods in Indonesia have been investigated in several studies. Past research found that consumer behaviour of organic food in North Sumatra using Theory of Reasoned Action (TRA) was able to provide a framework for studying the behaviour of consumer attitudes towards organic food. The result indicated that organic food knowledge, health knowledge and subjective norm variables were able to explain organic food purchases, while the cultural and the food attributes have no effect on attitudes [4].

From previous studies, Indonesian consumer choices with respect to organic food seem only to be analyzed based on attitude, social norms, socio-demographics (e.g., age, education, income, and children in the household) and health reasons. Meanwhile, consumer preferences towards organic food are complex; not only linking food to health, but also linking food to their awareness of the environment, attitudes toward organic products, trustworthiness of information, and behaviour to control Based on the above observation, the researcher is interested to analyze the influence of consumer behaviour to purchase organic food in Jakarta. The research aims to prove there is positive correlation among all theories of planned behaviour variables. Finally, based on findings, this research will then give suggestions to the organic food producers by creating and formulating a preferable marketing strategy to achieve better sales performance and to support organic foods growth in Jakarta. Since, we know that there is still a potential demand and market growth opportunity in the Indonesia market.

Based on the research problem, the author tries to identify and explain if below factors, based on theory of planned behaviour concept of (1) Attitude; (2) Subjective Norms; and (3) Perceived Behavioral Control, that has an influence on the intention of purchasing organic foods in Jakarta. Besides, this research also tries to identify the influence between intentions to purchase organic foods in Jakarta.

Consumer behaviour consists of ideas, feelings, experiences and actions of consumers with additional environmental factors, for instance, advertisement, prices and commends. Furthermore, consumer behaviour is a dynamic process, because of the continuous changes in ideas, perceptions and activities of consumers as an individual or in a group [5].

Theory of Planned Behaviour (TPB) is used to investigate people's purchase decisions. The Theory of Planned Behaviour extends the Theory of Reasoned Action with a third variable, Perceived Behavioural Control, i.e. expectations of the individual about conditions (e.g. time, money, prices) which ease or constrain the actual behaviour through the mediation of intentions to perform the behaviour [6-7]. TPB is normally taken to predict and explain consumer 
behaviour about food choice [8]. It is expected that the relative importance of attitude, subjective norm and perceived behavioural control varies in the prediction of intention, according to the different behaviours and situations [6].

Attitude is defined as the degree to which a person perceives the behavior based on favorable or unfavorable assessment [6-7]. Attitude is mentioned and used by the society so often with various meanings. Attitude is shaped selectively to compromise consumer needs and could be changed by external influences like; joining a new community, gaining more knowledge and environment of a person [9].

Subjective norm is defined as any social influence that may determine if the individual performs or does not perform the behavior which is influenced by the judgment of significant others (e.g., parents, spouse, friends, teachers). Perceived behavioral control is defined as the level of confidence an individual has about their ability to perform the behavior based on how easy or difficult they perceive its performance as it relates to hindrances or facilitators. This refers to a person's perception of the ease or difficulty of performing the behavior of interest. Perceived behavioral control varies across situations and actions, which results in a person having varying perceptions of behavioral control depending on the situation. This construct of the theory was added later, and created the shift from the Theory of Reasoned Action to the Theory of Planned Behavior [67].

Purchase decision making process is the stage where the consumer actually purchases the product. For measuring the purchase decision, it is mentioned that the purchase decision process consists of five stages: introduction needs, information search, evaluation of alternatives, purchase decision and behavior after purchase [10].

\section{METHOD}

Research design is a master plan that provides necessary methods and procedures for researchers to collect and analyze the needed information. Quantitative research seeks to quantify the data and applies some form of statistical analysis [11]. In other words, quantitative research is to investigate the relationship between independent variables and dependent variables in statistical ways. Results from quantitative research can be as predictive, explanatory and confirming. According to Sekaran \& Bougie, 2009, two types of investigation are (1) causal study and (2) correlation study. Causal study is a study which wants to describe the cause of one or more problems and is undertaken when the researcher wants to define the cause of one or more problems. Correlation study is a study which wants to describe the variables associated with the problem.
Researchers will use quantitative methods in collecting and analyzing the influence of consumer behaviour to purchase organic food. Data will then be investigated by using causal and correlation study on the variables that will influence the consumer behaviour to purchase organic food. At the end of research, conclusion and recommendation will be obtained based on the data analysis.

Conceptual research framework presented in Figure 2 describes the relationship between variables that will be observed in this research. The framework is using, Theory of Planned Behavior framework which has 3 independent variables, including attitude, subjective norms, perceived behavioural control, moderate variable which is intention to purchase and independent variable which is purchase decision [6-7]. This research will examine the influences of variables such as attitude, subjective norms, and perceived behavioural control to intention. In addition, there is to be assessed the relationship between intention to purchase decisions in organic food.

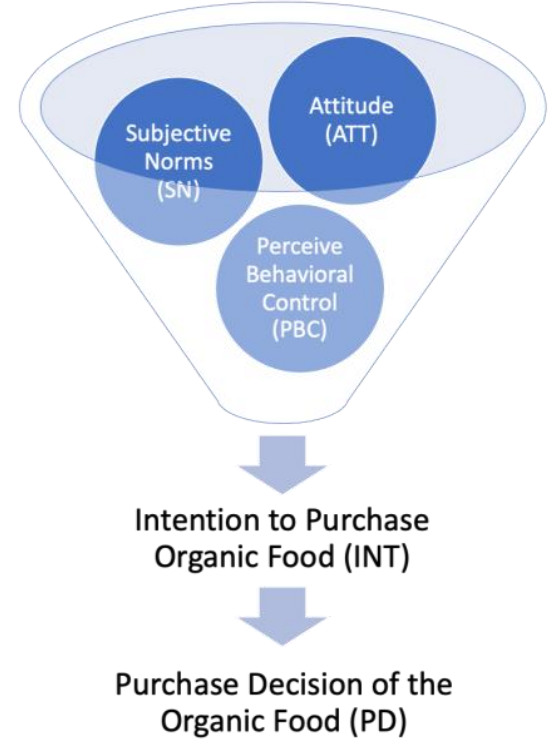

Figure 2. Research conceptual framework

Population refers to an entire group of people, events, things of interest that researchers wish to investigate [12]. Target population is a combination of all elements which share some common set of characteristics and possess the information sought by researchers. Target population for this research is consumers who stay in Jakarta region and have knowledge about organic food definition.

While using Structural Equation Modelling, one has to be careful about the sample size. SEM requires a large sample size [13]. More complex models may require the estimation of more statistical influences and thus larger samples are necessary in order for the results to be reasonably stable. SEM analysis requires sample sizes less than 100 would be considered small, 100 - 200 sample sizes are considered medium and is a better 
minimum and sample sizes exceeding 200 are considered large. The recommended sample size for SEM is 200 sample sizes [14]. In other words, any number above 200 is considered to provide sufficient data analysis for using SEM.

In order to conduct validity and reliability tests, a Pretest questionnaire will be tested on 30 samples for consumers who stay in Jakarta and know about organic foods. The primary questionnaire (post-test) will be tested to 400 samples based on the formulation of minimum sample size. Primary data refers to the information obtained directly by the researcher on the variables of interest for the specific purpose of the study and related to the problem required by the research objective, while secondary data refers to the information gathered from sources that already exist [12].

This research will use quantitative methods to analyze, evaluate and conclude the data by using both primary and secondary data. Primary data consists of questionnaires which will help researchers to identify variable influence to the consumer behaviour in organic food. Secondary data consists of external data, such as: organic foods growth, market and forecasts which will help researchers to gain insight towards consumer behaviour in organic food. Correlation between variables is a measure of how well the variables are related. Pearson correlation coefficient analysis is used to measure the strength of a linear relationship between two variables, which is measured using interval or ratio scales [15]. In this research, correlation coefficient was used to measure the strength of relationship between independent variables which is attitude, subjective norms, perceived behavioural control, intention and purchase decision.

Structural Equation Model (SEM) is a modelling technique widely used in behavioural research. SEM is a multivariate technique combining aspects of factor analysis, multiple regression analysis and path analysis that enables the researcher to simultaneously examine a series of interrelated dependence relationships among the measured variables and latent constructs as well as between several latent constructs [16]. A latent variable is one which cannot be directly observed or indicators and therefore needs to specify through a combination of observed variables.

SEM is a comprehensive analysis method that can model interactions, correlations between independent variables, measurement errors and their correlation, as well as multiple latent independent and dependent variables in which cooperating mediator variables into one comprehensive step while reducing the possibility for specification error. The main goal of SEM is to find the extent to which a hypothesis model fits or adequately describes sample data. The fitness of a model could be tested using a number of Goodness of fit (GOF). Measurement model's validity depends on establishing acceptable levels of goodness of fit (GOF) for the measurement which indicates how well the specified model reproduces the observed covariance matrices. The smaller the difference between covariance matrices is estimated with the observe covariance matrices [16]. GOF value contains seven tools to test the overall model whether it fitted with parameter or vice versa.

\section{RESULTS}

The research conceptual framework being built by using the help of the LISREL program. The program will develop the framework model and link with the data gathered from the research. The model then will be called a path diagram. Path diagram was built using LISREL version 8.8. LISREL provides the connection between attitude, subjective norms, perceived behavioral control, intention to purchase and purchase decision. The latent, endogenous and exogenous variables need to be defined clearly in the model to avoid mistakes in the model (Figure 3)

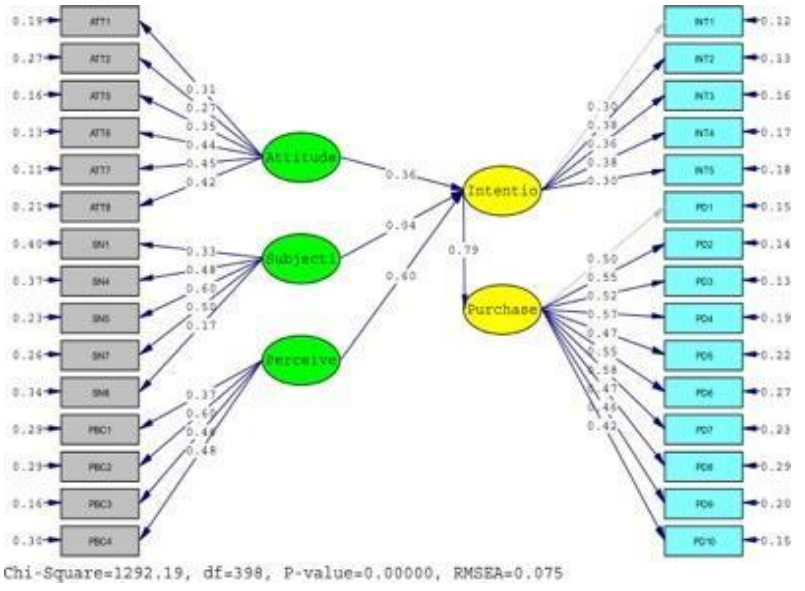

Figure 3. Structural equation model (SEM) and path coefficient in the path diagram

Based on the RMSEA, researchers repair the model as much as to fit the model. Reparation of the model was done by eliminating indicators with the consideration of repeating questions, small validity output from the pretest or weak correlation showing in the path diagram.

Chi square result $\mathrm{p}=0.0$, while the estimated $\mathrm{p}>0.05$. Different covariance matrices estimate within the covariance matrices observed, smaller (X2) shows the difference of both not significant and the model more fit (Table 1). It can be concluded that the model is fit.CMIN/df, CMIN represents the minimum value of the discrepancy while $\mathrm{df}$ is the degree of freedom. CMIN/df ratio values lower than 2 are widely considered to represent a minimally plausible model, while the model resulting $\mathrm{CMIN} / \mathrm{df}$ is 0 . It can be concluded that the model is fit. RMSEA, is the most popular goodness of fit indices. RMSEA values over 0.08 indicate that the model needs to be repaired. In this model, RMSEA result is 0.075 , which means that the model was fit. 
Table 1. Goodness of fit criteria

\begin{tabular}{lccc}
\hline Goodness of Fit Index & Cutt-off Value & Value & Result \\
\hline Chi Square & Smaller is better $(\mathrm{p}<0.05)$ & 0 & Fit \\
\hline The Minimum Sample Discrepancy Function (CMIN/DF) & $\leq 5.00$ & 0 & Fit \\
\hline The Root Mean Square Error of Approximation (RMSEA) & $\leq 0.08$ & 0.075 & Fit \\
\hline Goodness of Fit Index (GFI) & $\geq 0.90$ & 0.82 & Not fit \\
\hline Relative Fit index (RFI) & $\geq 0.90$ & 0.94 & Fit \\
\hline Comparative Fit Index (CFI0 & $\geq 0.90$ & 0.96 & Fit \\
\hline
\end{tabular}

Goodness Fit Index (GFI) is the value between 0 1. According to Hair et al (2010), the greater the value, the more fit of the model. The cut off value is greater and equal to 0.9 . In this model, the GFI result is 0.82 , which means that model does not fit. Normed Fit Index $(\mathrm{NFI})=$ 0.94 means that the model is fit, because NFI has passed the fit index which NFI > 0.9. Comparative Fit Index $(\mathrm{CFI})=0.96$ means that the model is fit, because CFI has passed the fit index which CFI > 0.9. CFI is not affected by sample size.

Based on Table 1, chi-square, CMIN/DF, RMSEA, NFI and CFI are showing a good result (fit) to conclude that the model was fit to the data. Therefore, the assumption of a causal model which has been explained before already provides statistical support. Meanwhile, GFI (0.82) shows that the model is close to fit. However, RMSEA is the most popular goodness of fit indices that can be concluded that the model is fit.

Path analysis diagram used in this research was designed to analyze the research hypothesis, which is to see the influence of attention to intention to purchase organic foods, influence of subjective norms to intention to purchase organic foods, influence of perceived behavioral control to purchase organic foods and intention to purchase decisions on organic foods. LISREL version 8.8 was used to develop the path coefficients from the correlation created between the independent and dependent variables using maximum likelihood (MLE). MLE estimates path (regression) coefficients using an iterative procedure to approximate parameters in order to fit the data to the model.
Path coefficient is a standardized regression coefficient that will provide a statistically reliable measurement to test on the influence of the independent and dependent variables to answer the research hypothesis. Table 2 shows the estimated coefficient and $\mathrm{t}$-value of the path diagram model. Path coefficient is a standardized regression coefficient that will provide a statistically reliable measurement to test on the influence of the independent and dependent variables to answer the research hypothesis. Table 2 shows the estimated coefficient and t-value of path diagram model.

\section{HYPOTHESIS TESTING}

Inferential statistics including path correlation (regression) was employed to test the correlation between research variables, in which attitude, subjective norms, perceived behavioral control, intention to purchase and purchase decision. Means was also used as part of descriptive statistical analysis of each variable indicator.

\subsection{Testing of the Research Hypothesis \#1}

Hypothesis \#1: There is an influence between attitude and intention on purchasing organic foods in Jakarta.

- H0 \#1 : There is no influence of attitude on the intention of purchasing organic foods in Jakarta

- H1 \#1 : There is an influence of attitude on the intention of purchasing organic foods in Jakarta

Table 2. Estimate coefficient and t-Value of path diagram mode

\begin{tabular}{lcccc}
\hline Structural Relationship & $\begin{array}{c}\text { Standardized } \\
\text { Regression Weight (r) }\end{array}$ & t-Value & $\begin{array}{c}\text { Strength of } \\
\text { Association }\end{array}$ & T-Analysis \\
\hline $\begin{array}{l}\text { Attitude } \rightarrow \\
\text { Intention to Purchase }\end{array}$ & 0.36 & 6.67 & Weak & Significant \\
\hline $\begin{array}{l}\text { Subjective Norms } \rightarrow \\
\text { Intention to Purchase }\end{array}$ & 0.04 & -0.84 & None & Not significant \\
\hline $\begin{array}{l}\text { Perceived Behavioral Control } \rightarrow \\
\text { Intention to Purchase }\end{array}$ & 0.60 & 8.89 & Strong & Significant \\
\hline $\begin{array}{l}\text { Intention to Purchase } \rightarrow \\
\text { Purchase Decision }\end{array}$ & 0.79 & 11.69 & Very Strong & Significant \\
\hline
\end{tabular}


Table 2 demonstrates the standardized regression coefficient of attitude and intention to purchase organic foods. Since the standardized regression weight is 0.36 , meaning that has "weak" correlation between variables with t-value is 6.67 , not in between $-1.96-1.96$ conclude that has significance between attitude and intention to purchase organic foods. Therefore, it resulted to reject null hypothesis ( $\mathrm{H} 0$ \#1) and accepted the hypothesis ( $\mathrm{H} 1$ \#1). It could be noted that there is an influence between attitude to intention on purchasing organic foods in Jakarta.

In order to get better analysis on the relationship, statistical descriptives are performed that show that the attitude variables are influenced by knowledge and food attributes. The table 3 shows that the strong important factor influencing the attitude is under healthiness aspect.
Attitude is shaped selectively to compromise consumer needs and could be changed by external influences like; joining a new community, gaining more knowledge and environment of a person [9]. Healthy, safety, and quality of the food give positive attention to the consumer for their intention in purchasing organic food. While, general knowledge has also resulted in a correlation to intention.

Another important finding in the past results were that positive attitude towards organic products, safety and health, environmental concerns, as well as degree of trust in organic attributes, are the determinants of organic vegetable purchasing among consumers. So, as a company should see the new product emerge in the market or existing products future demand can be predicted by measuring consumer attitude [17].

Table 3. Descriptive statistic output of attitude, subjective norms, perceived behavioral control, and intention variables

\begin{tabular}{|c|c|c|c|c|c|}
\hline Variables & $\begin{array}{l}\text { Indicator } \\
\text { Value }\end{array}$ & Indicator & $\begin{array}{l}\text { Standardized } \\
\text { Regression } \\
\text { Weight (r) } \\
\end{array}$ & Mean & $\begin{array}{l}\text { Standard } \\
\text { Deviation }\end{array}$ \\
\hline \multirow[t]{6}{*}{ Attitude } & ATT1 & Organic food is free from chemical & 0.31 & 3.22 & 0.537 \\
\hline & ATT2 & $\begin{array}{l}\text { I buy organic food after knowing clearly } \\
\text { on definition, process, and benefit }\end{array}$ & 0.27 & 3.16 & 0.589 \\
\hline & ATT5 & $\begin{array}{l}\text { Consuming organic food is an act to } \\
\text { maintain health }\end{array}$ & 0.35 & 3.24 & 0.532 \\
\hline & ATT6 & Organic food is safer for consumption & 0.44 & 3.2 & 0.574 \\
\hline & ATT7 & Organic food is healthier for the body & 0.45 & 3.2 & 0.559 \\
\hline & ATT8 & Organic food has better quality & 0.42 & 3.23 & 0.621 \\
\hline \multirow[t]{5}{*}{$\begin{array}{l}\text { Subjective } \\
\text { Norms }\end{array}$} & SN1 & $\begin{array}{l}\text { Ethnic affects my habit of consuming } \\
\text { organic food }\end{array}$ & 0.33 & 2.42 & 0.714 \\
\hline & SN4 & $\begin{array}{l}\text { Family background affects my habit of } \\
\text { consuming organic food }\end{array}$ & 0.48 & 2.85 & 0.770 \\
\hline & SN5 & $\begin{array}{l}\text { Work affects my habit of consuming } \\
\text { organic food }\end{array}$ & 0.60 & 2.66 & 0.766 \\
\hline & SN7 & $\begin{array}{l}\text { Community / friends affect my habit of } \\
\text { consuming organic food }\end{array}$ & 0.50 & 2.83 & 0.715 \\
\hline & SN8 & $\begin{array}{l}\text { I buy organic food because I love healthy } \\
\text { life style }\end{array}$ & 0.17 & 3.05 & 0.605 \\
\hline \multirow{4}{*}{$\begin{array}{l}\text { Perceived } \\
\text { Behavioral } \\
\text { Control }\end{array}$} & PBC1 & Organic food is easy to find around me & 0.37 & 2.84 & 0.655 \\
\hline & PBC2 & $\begin{array}{c}\text { Price does not affect me in buying } \\
\text { organic food }\end{array}$ & 0.60 & 2.60 & 0.808 \\
\hline & PBC3 & $\begin{array}{c}\text { Benefit of organic food is proportional to } \\
\text { price }\end{array}$ & 0.46 & 2.94 & 0.606 \\
\hline & PBC4 & $\begin{array}{l}\text { Healthy lifestyle and slogan "back to } \\
\text { nature" in the mass media influenced me } \\
\text { to buy organic food }\end{array}$ & 0.48 & 2.79 & 0.728 \\
\hline \multirow{5}{*}{$\begin{array}{l}\text { Intention } \\
\text { to } \\
\text { Purchase }\end{array}$} & INT1 & I intend to buy organic food products & 0.30 & 3.08 & 0.457 \\
\hline & INT2 & I choose organic food in the long run & 0.38 & 3.02 & 0.530 \\
\hline & INT3 & $\begin{array}{l}\text { Providing nutritional food to the family } \\
\text { by buying organic food }\end{array}$ & 0.36 & 3.17 & 0.540 \\
\hline & INT4 & $\begin{array}{l}\text { Family will be healthy by consuming } \\
\text { organic food }\end{array}$ & 0.38 & 3.13 & 0.557 \\
\hline & INT5 & $\begin{array}{l}\text { I will buy organic food after knowing its } \\
\text { health benefit }\end{array}$ & 0.30 & 3.11 & 0.524 \\
\hline
\end{tabular}




\subsection{Testing of the Research Hypothesis \#2}

Hypothesis \#2: There is an influence between subjective norms on the intention on purchasing organic foods in Jakarta.

- $\quad \mathrm{H} 0 \# 2$ : There is no influence of subjective norms on the intention on purchasing organic foods in Jakarta.

- $\quad \mathrm{H} 1$ \#2 : There is an influence of subjective norms on the intention on purchasing organic foods in Jakarta.

Table 2 demonstrates the standardized regression coefficient of subjective norms and intention to purchase organic foods. Since the standardized regression weight is 0.04 , meaning that has "none" correlation between variables with $\mathrm{t}$-value is -0.84 , in between $-1.96-1.96$ conclude that has no significance between subjective norms and intention to purchase organic foods. Therefore, it resulted to accept null hypothesis ( $\mathrm{H} 0$ \#2) and rejected the hypothesis (H1 \#2). It should be noted that there is no influence subjective norms to intention on purchasing organic foods in Jakarta.

In order to get better analysis on the relationship, statistical descriptives are performed to show that the subjective norms variables are influenced by culture, social and family. The table 3 shows that the strong important factor influencing the subjective norms is work affects on habit to consume organic food, followed by community / friends, family background and ethnic.

According to the result it can be summarized that the subjective norms have not influenced the intention. Culture is the circulation of the values, norms and traditions among the society between the generations [18]. TRA and TPB which have been widely applied in Western cultures, however it is not clear that the assumptions are well suited to other cultures [19]. This research resulted in Western culture not suited to the Eastern culture because different cultures have different ethnic, social class, and family culture.

In addition, a contradiction found from the past research of organic food purchase decisions in Medan, North Sumatera, was that the subjective norms were able to explain organic food purchases. As we know, Jakarta has very bad traffic for all the weekdays and sometimes on the weekend. Therefore, Jakarta citizens in our current research have spent less time with their family in a day, while Medan, the third largest citizen in Indonesia have more time to spend with family. Due to the bad traffic, Jakarta citizens have spent most of their time at the office or traveling. Therefore, the result found correctly that it works as a very important indicator to influence on the subjective norms.

Finally, it is thought that intention is likely to be a dynamic concept, constantly under re-evaluation by the consumer as situations change or as more information becomes available.

\subsection{Testing of the Research Hypothesis \#3}

Hypothesis \#3: There is an influence perceived behavioural control to intention on purchasing organic foods in Jakarta.

- H0 \#3 : There is no influence of perceived behavioural control to intention on purchasing organic foods in Jakarta.

- H1 \#3 : There is an influence of perceived behavioural control to intention on purchasing organic foods in Jakarta.

Table 2 demonstrates the standardized regression coefficient of perceived behavioural control and intention to purchase organic foods. Since the standardized regression weight is 0.6 , meaning that has "strong" correlation between variables with t-value is 8.89 , not in between -1.96 - 1.96 conclude that has significance between perceived behavioural control and intention to purchase organic foods.

Therefore, it resulted to reject null hypothesis ( $\mathrm{H0} \mathrm{\# 3)}$ and accepted the hypothesis (H1 \#3). It could be noted that there is an influence of perceived behavioural control to intention on purchasing organic foods in Jakarta.

Table 2 demonstrates the standardized regression coefficient of perceived behavioural control and intention to purchase organic foods. Since the standardized regression weight is 0.6 , meaning that has "strong" correlation between variables with t-value is 8.89 , not in between $-1.96-1.96$ conclude that has significance between perceived behavioural control and intention to purchase organic foods. Therefore, it resulted to reject null hypothesis ( $\mathrm{H} 0$ \#3) and accepted the hypothesis (H1 \#3). It could be noted that there is an influence of perceived behavioural control to intention on purchasing organic foods in Jakarta.

In order to get better analysis on the relationship, statistical descriptives are performed to show that perceived behavioural control variables are influenced by price, availability of product and advertisement. Price still taking a control on buying, which previous research is also state that price is an influence to the purchase decision. The table 3 shows that the strong important factor influencing perceived behavioural control is under price then organic slogan. While availability of product is showing a weak influence to perceived behavioural control.

Perceived behavioral control is defined as the level of confidence an individual has about their ability to perform the behavior based on how easy or difficult they perceive its performance as it relates to hindrances or facilitators [6-7]. In addition to factors affecting perceived behavioural control, participants were very sensitive to the price, availability and advertisement that affecting their personal intentions. The price sensitivity 
was also applied to the past result on organic food in Sulawesi and Turkish.

\subsection{Testing of the Research Hypothesis \#4}

Hypothesis \#3: There is an influence of intention to purchaser toward purchase decision of organic foods in Jakarta.

- $\quad$ H0 \#4 : There is no influence of intention to purchaser toward purchase decision of organic foods in Jakarta.

- $\quad \mathrm{H} 1$ \#4 : There is an influence of intention to purchaser toward purchase decision of organic foods in Jakarta.

Table 2 demonstrates the standardized regression coefficient of intention to purchase organic foods towards purchase decision of organic foods. Since the standardized regression weight is 0.79 meaning that has "very strong" correlation between variables with t-value is 11.69 , not in between $-1.96-1.96$ conclude that has significance between intentions to purchase to purchase decision. Therefore, it resulted to reject null hypothesis (H0 \#4) and accepted the hypothesis (H1 \#4). It could be noted that there is an influence on purchasing organic foods to purchase decision of organic foods in Jakarta.

Purchase decision making process is the stage where the consumer actually purchases the product. For measuring the purchase decision, it is mentioned that the purchase decision process consists of five stages: introduction needs, information search, evaluation of alternatives, purchase decision and behavior after purchase [10]. The table 3 shows that the strong important factor influences intention. Statistic descriptive is performed as it shows that intention variables are influenced by choosing organic food in the long run and family. The rest of intention indicators also show a positive correlation between intentions.

In addition, researchers found a contradictive answer where consumers have a strong intention to purchase organic food, while at perceived behavioural control found that consumers were very sensitive to the price. This means that consumers not only took price as their consideration to purchase organic food but health, safety, quality from that created consumer attention was also being considered.

\section{CONCLUSION}

The primary aim of this thesis is to analyze the influence factors of theory planned behaviour such as attitude, subjective norms, perceived behavioural control to intentions as the mediator to purchase organic foods in Jakarta. This research concludes that there are significant influences and correlation at attitude and perceived behavioural control to intention and intention as mediators have very strong influence and correlation to purchase decisions of organic foods in Jakarta.
Meanwhile, the subjective norm is not influencing and correlating to intentions of purchasing organic foods.

First, there is an influence between attitude and intention on purchasing organic foods in Jakarta. Consumers put more concern on the food indicators, which the most is about its healthiness, followed by safety and quality. It aligns with the consumer behaviour information that one of the most important reasons behind purchasing organic foods is safety reasons. Second, there is no influence on the subjective norms of intention on purchasing organic foods in Jakarta because culture, social, family and friends are not giving any influence to the consumer on purchasing organic foods. TRA and TPB which have been widely applied in Western cultures has not suitable for Eastern cultures. Especially in Jakarta, where people spend more time at the office than home. Third, there is an influence of perceived behavioural control to intention on purchasing organic foods in Jakarta. Consumers are concerned about the price and also advertisements to have the intention to purchase the organic foods compared to availability of organic food products in the market. As long as the organic food price is cheap, consumers will purchase organic products although it is difficult to find in the market.

In addition, the last research hypothesis proves that there is an influence between intention on purchasing organic foods to purchase decisions of organic foods in Jakarta. It has a "very strong" correlation between intentions to the purchase decision of organic foods. Among these three independent variables, perceived behavioural control is the most influential factor to intentions which conclude where availability, price and advertisement are very important for consumers to make the purchase decision. Therefore, as an organic company needs to think on marketing strategy to have promotion campaigns in order to boost the increment of sales revenue, product awareness and consumer loyalty of the organic products. Moreover, consumers who purchase the brand frequently resist switching to another brand. Jean-Louse (2011) mentioned that consumers intend to purchase because they think they have the right price quality relation. Consumers who are satisfied with the product will have a positive attitude towards the brand and later have influence on purchase intention.

Beside the results, the main significant difference with the previous study is that this research is using theory of planned behaviour while adding the perceived control behaviour as the influencing variable to the intentions

\section{RECOMMENDATION}

According to the recommendations collected from the respondents, it would suggest that further research could continue forward by enlarge the scope of study either 
vertically by adding the research variables, or horizontally by enlarge the population or research target. The number of respondents can be added to reflect better representation of the overall population and focus on the specific organic foods, such as vegetables which respondents want to consume.

Government needs to support the production of organic products such as plantation, technology, and regulation. Therefore, the most important relation to consumer intention such as perceived behavioral control could be solved. Perceived behavioral control of consumers consist of availability of the products, price and advertisement. In addition, price is one of the most influential indicators of the intention of purchasing organic foods, which means that for further research, researchers can research the price elasticity of organic foods. Moreover, organic food producers / companies should also think on marketing strategy on promotion campaigns to increase product awareness and consumer loyalty of the organic products.

Last but not least, researchers hope that Indonesia's organic foods supply and demand can grow significantly both domestically and also as an export market.

\section{REFERENCES}

[1] Hsieh, S.C., 2004. We need more efforts for organic food certification (in Chinese) Proceed. Symposium on strategies of agricultural development in Kaohsiung and Pingtung regions in Taiwan pp. 5763. Printed by National Pingtung University of Science and Technology. Hunt, D.P., 2003

[2] FiBL survey 2017, World Organic Agricultural Land by Region: Growth 2014 - 2015, based on data from government bodies, private sector and certifiers, 2014-2015.

[3] FiBL-IFOAM-SOEL, Growth of Organic Agricultural Land and Organic Share 1999 - 2015, surveys 1999- 2017.

[4] Effendi, I., Ginting, P., Lubis, A.N., and Fachruddin, K.A. 2002. Analysis of Consumer Behavior of Organic Food in North Sumatra Province, Indonesia, Journal of Business and Management.

[5] Peter, P. J., \& Olson, C. J. 2010. Consumer Behavior \& Marketing Strategy. McGraw-Hill/Irwin. Sanusi, A., 2011. Metodologi Penelitian Bisnis. Jakarta: Penerbit Salemba 4.

[6] Ajzen, I. (1985), From intentions to actions: A theory of planned behaviour. In: Kuhl, J. and Beckmann, J. (eds.): Action control: From cognition to behaviour. New York: Springer.
[7] Ajzen I., Joyce N., Sheikh S., Gilbert Cote N. (2011). Knowledge and the prediction of [Ajzen I. (2012). The theory of planned behavior.

[8] Thorgersen, J. 2000. Psychological determinants of paying attention to eco-labels in purchase decisions: model development and multinational validation. Journal of Consumer Policy, v. 23, p. 235-313. West Sussex: John Wiley \& Sons Ltd.

[9] Chisnall, P. Strategic Business Marketing (1995, Paperback) ISBN-10: 0132033658 | ISBN-13:

[10] Armstrong, K. P. (2012). Principles of Marketing. New York: Pearson Education.

[11] Malhotra, N.K., 2008. Marketing Research, An Applied Orientation. 4th ed. S.1.: Upper Saddle River, NJ, Prentice Hall Inc.

[12] Sekaran, U. \& Bougie, R., 2009. Research Methodology for Business - A Skill Building Approach. 5th ed.

[13] Kline, R.B. 2005. Principles and practice of structural equation modelling. 2nd ed. New York: Guilford Press.

[14] Sivo, S., Saunders, C., Chang, Q \& Jiang, J., 2006. How Low Should You Go? Low Response Rates and the Validity of Inference in IS Questionnaire Research. Journal of the Association for Information Systems, pp. 351- 414

[15] Zikmund, W.G. \& Babin, B. J., 2010. Exploring Marketing Research. 10th ed. Australia: SouthWestern / Cengage Learning

[16] Hair, J.F. et al., 2010. Multivariate Data Analysis. 7th ed. New Jersey: Pearson Education Inc

[17] Blackwell, R., Miniard, P. and Engel (2001) Consumer behavior. Ohio: South-Western, The Dryden Press. Burns, A.C. \& Bush, R. F., 2006. Marketing Research. 5th ed. New Jersey, USA: Pearson Education, Inc.

[18] Solomon M., Bamossy G, Askegaard S. 2002. "Consumer Behaviour-A European Perspective. Prentice Hall.

[19] Solomon M., Bamossy G, Askegaard S. 2002. "Consumer Behaviour-A European Perspective. 